\title{
About the stability of platform on which we build mathematical knowledge at the engineering universities
}

\author{
S. Tsedendamba ${ }^{1}$, K. Dishlieva ${ }^{2}$, S. Petkova ${ }^{3}$ \\ ${ }^{I}$ Department of Mathematics, Mongolian University of Science and Technology, Mongolia \\ ${ }^{2}$ Faculty of Applied Mathematics and Informatics, Technical University of Sofia, Bulgaria \\ ${ }^{3}$ Department of Mathematics, University of Chemical Technology and Metallurgy - Sofia, Bulgaria
}

\begin{abstract}
Determination and establishment of the students' knowledge and skills in mathematics is an important task not only for the lecturers but also for the learners. The authors examine the role and results of one diagnostic test used before the topic of differential calculus in three technical universities. Interpretation of the results and timely adequate reactions are almost compulsory.
\end{abstract}

Keywords: diagnostic test, mathematics education; survey Likert-type scale; secondary-tertiary degree transition

\section{Introduction}

The problems of mathematical education for engineering students are very important. The report of European Society for Engineering Education (SEFI, 2013) is used as a base for creating mathematics curriculum for engineering training. After many discussions, a detailed and structured list of topics and the learning outcomes have been formulated. The aim is to optimize the organization of educational process and achieve the desired level of mathematical knowledge and skills, and their evaluation. Different competencies, knowledge, and skills to specific mathematical content are given. The learning outcomes are arranged in four levels that reflect the hierarchical structure of mathematics and the way it can be progressively refined and associated with the real applications in engineering curricula. Pre-requisite knowledge (Core Zero), see [1,2] is assumed as an essential base for Core Level 1 and beyond. There are various options for the students' admission at the Technical universities and some kind of diagnostic testing and additional support is needed throughout the first year in order to help the students who may be deficient in some areas.

\section{Motivation}

Usually, the teachers do not have prior information about their students, see [3, 4]. But, for the lectures and tutors, it is very important to obtain a clear picture of actual knowledge and computational skills of their students on the specific topics which will enable for an adequate training organization and individual approach depending on the specific students' demands, see [7]. Also, it is useful for the students to understand their gaps and mistakes which can be the obstacles (sometimes serious) to their successful future training, see [5, 6].

The authors propose an anonymous survey and diagnostic test which could be used before calculus topics. The test is not based on the classical theory for independent assessment and does not have the qualities of entrance exam. This is one "snapshot" of the students' current knowledge and skills as a necessary base for upgrading. The correct interpretation of the results and timely adequate reactions are necessary and useful. Some mathematical concepts are presented in the survey and the students have to determine to what extent they are ready to use them. In the test, there are six examples; first, second and fourth do not require calculations, while the other three check basic knowledge and some computational skills. It was explained that the aim of this test is to clarify the students' demands and difficulties in order to improve the quality of their education. The processed information will be published in an appropriate way and they will be able to familiarize with the results obtained. This investigation is a part of a comparative study about education and comprises also three surveys. The results are published in [3,5 and 6].

The respondents are 90 students first year of:

\section{Respondents}

- German Preparatory Course (Group A), School of Applied Sciences at the Mongolian University of Science and Technology in Ulan Bator (MUST) - 25 students;

- Centers in German and French Language Education (Group B), Faculty of International Academic Mobility and Language Training at the University of Chemical Technology and Metallurgy in Sofia, (UCTM), Bulgaria - 25 students;

- English Language Faculty of Engineering (Group C), Technical University of Sofia (TU-Sofia), Bulgaria 40 students. 
The materials for group A were written in Mongolian language and for Groups B and C in Bulgarian. The survey and test start with six supplementary questions about the faculty of students interviewed, gender, year of the graduation, type and place of the secondary school; the number of math classes per week, the form of studying - mandatory training, mandatory elective courses and/or extracurricular courses.

Some facts about the assessments at the baccalaureate (mature), the diploma, and Entrance test for (for Bulgarian universities) are given in Table 1.

\begin{tabular}{|l|c|c|c|}
\hline \multicolumn{1}{|c|}{ University } & MUST-Group A & UCTM-Group B & TU-Sofia-Group C \\
\hline $\begin{array}{l}\text { Average math classes per week for the } \\
\text { secondary educational degree }\end{array}$ & 4.75 & 2.5 & $3.16(2-8)$ \\
\hline Average grade for the admission & $608(\max 800)$ & $4.63(\max 6.00)$ & $21.02(\max 30)$ \\
\hline
\end{tabular}

Table 1

After the poll and test the individual conversations were conducted with approximately $50 \%$ of Mongolian students and $70 \%$ of Bulgarian students.

\section{Main Results}

In the first part, 33 mathematical concepts of the school course are included and the respondents have to determine to what extent they know them. The authors use 6-points Likert scale to specify correctly their opinion: "Yes", "More Yes than No", "Yes and No", "More No than Yes", "No" and "I do not know" for all the answers: I am not sure, I cannot decide, I cannot solve, I hesitate, I can't determine, I do not remember. A part of the results obtained are given in Table 2.

\begin{tabular}{|c|c|c|c|c|c|c|c|c|c|c|c|c|c|c|c|c|c|c|}
\hline 7 Scale & \multicolumn{3}{|c|}{ Yes } & \multicolumn{3}{|c|}{$\begin{array}{c}\text { More Yes } \\
\text { than No }\end{array}$} & \multicolumn{3}{|c|}{ Yes and No } & \multicolumn{3}{|c|}{$\begin{array}{l}\text { More No } \\
\text { than Yes }\end{array}$} & \multicolumn{3}{|c|}{ No } & \multicolumn{3}{|c|}{$\begin{array}{l}\text { I do not } \\
\text { know }\end{array}$} \\
\hline Concepts & $\mathrm{A}$ & $\mathrm{B}$ & $\mathrm{C}$ & $\mathrm{A}$ & $\mathrm{B}$ & $\mathrm{C}$ & $\mathrm{A}$ & $\mathrm{B}$ & $\mathrm{C}$ & $\mathrm{A}$ & B & $\mathrm{C}$ & $\mathrm{A}$ & $\mathrm{B}$ & $\mathrm{C}$ & $\mathrm{A}$ & $\mathrm{B}$ & $\mathrm{C}$ \\
\hline Natural Numbers & 12 & 17 & 38 & 3 & 2 & 1 & 5 & 1 & 1 & 1 & 1 & 0 & 0 & 3 & 0 & 4 & 1 & 0 \\
\hline Whole Numbers & 14 & 23 & 35 & 2 & 1 & 2 & 4 & 1 & 2 & 1 & 0 & 1 & 0 & 0 & 0 & 4 & 0 & 0 \\
\hline Rational Numbers & 12 & 22 & 31 & 3 & 1 & 4 & 4 & 1 & 0 & 2 & 0 & 2 & 0 & 1 & 0 & 4 & 0 & 3 \\
\hline Irrational Numbers & 13 & 20 & 37 & 0 & 1 & 1 & 5 & 1 & 1 & 1 & 0 & 1 & 0 & 3 & 0 & 6 & 0 & 0 \\
\hline Real Numbers & 11 & 23 & 34 & 4 & 0 & 6 & 4 & 0 & 0 & 2 & 0 & 0 & 0 & 1 & 0 & 4 & 1 & 0 \\
\hline Logarithm & 9 & 20 & 32 & 2 & 2 & 5 & 9 & 0 & 1 & 0 & 0 & 0 & 0 & 1 & 0 & 5 & 2 & 2 \\
\hline Absolute Value & 4 & 19 & 25 & 6 & 2 & 9 & 9 & 1 & 2 & 0 & 0 & 0 & 0 & 1 & 0 & 6 & 2 & 4 \\
\hline Function & 12 & 21 & 37 & 3 & 1 & 3 & 5 & 0 & 0 & 1 & 1 & 0 & 0 & 0 & 0 & 4 & 2 & 0 \\
\hline Domain & 5 & 18 & 32 & 6 & 0 & 2 & 6 & 1 & 0 & 1 & 1 & 0 & 0 & 1 & 0 & 7 & 5 & 6 \\
\hline Linear Function & 9 & 23 & 38 & 8 & 0 & 2 & 3 & 1 & 0 & 1 & 0 & 0 & 0 & 0 & 0 & 4 & 1 & 0 \\
\hline Quadratic Function & 10 & 23 & 38 & 6 & 0 & 2 & 4 & 0 & 0 & 1 & 0 & 0 & 0 & 1 & 0 & 4 & 1 & 0 \\
\hline Polynomial & 9 & 16 & 29 & 5 & 3 & 3 & 5 & 0 & 0 & 0 & 1 & 0 & 0 & 2 & 2 & 6 & 3 & 6 \\
\hline Power Function & 7 & 14 & 31 & 8 & 0 & 2 & 5 & 1 & 2 & 0 & 4 & 0 & 0 & 0 & 0 & 5 & 6 & 5 \\
\hline Rational Function & 10 & 15 & 25 & 5 & 3 & 5 & 5 & 1 & 2 & 1 & 2 & 0 & 0 & 0 & 0 & 4 & 4 & 8 \\
\hline Exponential F-n & 10 & 12 & 20 & 5 & 1 & 3 & 4 & 2 & 3 & 1 & 2 & 0 & 0 & 2 & 7 & 5 & 7 & 7 \\
\hline Logarithmic F-n & 6 & 15 & 26 & 9 & 2 & 6 & 4 & 0 & 2 & 2 & 1 & 2 & 0 & 2 & 0 & 4 & 5 & 4 \\
\hline Trigonometric F-n & 11 & 19 & 32 & 6 & 2 & 6 & 3 & 0 & 0 & 1 & 1 & 0 & 0 & 2 & 0 & 4 & 1 & 2 \\
\hline Irrational Function & 7 & 16 & 32 & 10 & 2 & 4 & 3 & 0 & 0 & 0 & 2 & 0 & 0 & 1 & 0 & 5 & 4 & 4 \\
\hline Coordinate System & 11 & 22 & 38 & 6 & 0 & 2 & 3 & 0 & 0 & 1 & 2 & 0 & 0 & 0 & 0 & 4 & 1 & 0 \\
\hline
\end{tabular}

Table 2

The second part consists of six questions. Three of them (examples 1,2 and 4) do not require calculations, while the other three check basic knowledge and computational skills.

In Example 1, the students have to determine if the given statements are true or false and the results obtained are given in Table 3 .

\begin{tabular}{|c|l|c|c|c|c|c|c|c|c|c|}
\hline \multirow{2}{*}{$\mathrm{n}$} & \multicolumn{3}{|c|}{ Number } & \multicolumn{3}{|c|}{ Correct Answers } & \multicolumn{3}{c|}{ Wrong Answers } & \multicolumn{3}{|c|}{ I do not know } \\
\cline { 2 - 13 } & A & B & C & A & B & C & A & B & C \\
\hline 1 & $-2 \notin Z$ & 13 & 12 & 20 & 3 & 5 & 7 & 9 & 8 & 13 \\
\hline 2 & $2 / 3 \in Q$ & 12 & 15 & 30 & 4 & 6 & 3 & 9 & 4 & 7 \\
\hline 3 & $0,25.10^{3} \in N$ & 9 & 8 & 19 & 7 & 7 & 14 & 9 & 10 & 7 \\
\hline 4 & $\sqrt{3} \notin Q$ & 8 & 6 & 17 & 7 & 4 & 11 & 10 & 15 & 12 \\
\hline 5 & $\sqrt{-1} \notin R$ & 12 & 14 & 24 & 3 & 2 & 10 & 10 & 9 & 6 \\
\hline
\end{tabular}

Table 3 
About the stability of platform on which we build mathematical knowledge at the engineering ..

The Histograms 1, 2 and 3 reflect the answers of examples 1.1, 1.3, 1.4. The summarized results are given by Histogram 4. During the individual conversations with the students, it was clarified that the negative statements have been causing for the wrong answers.
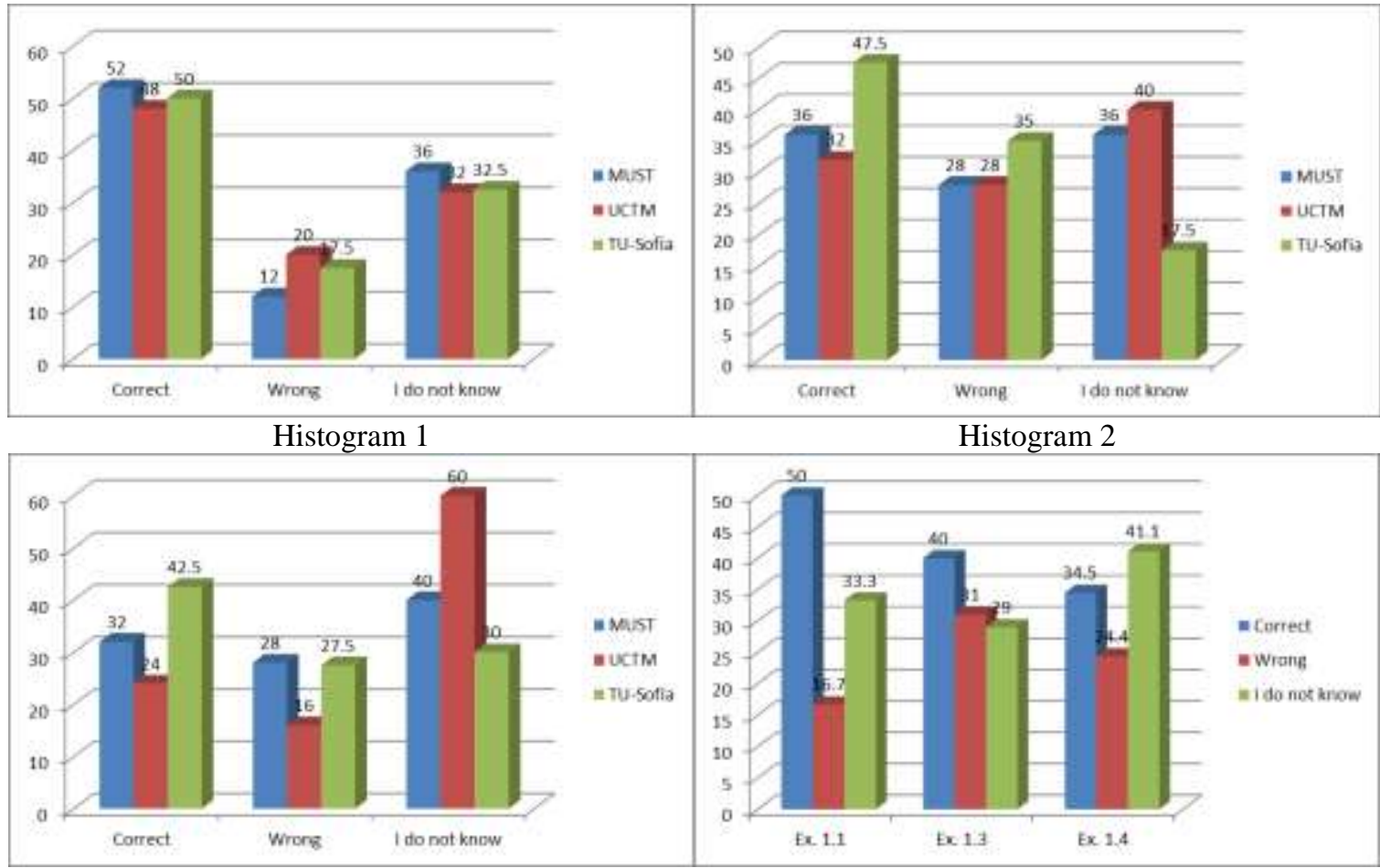

Histogram 3

Histogram 4

In Example 2, the students have to identify the type of the following functions:

$$
f(t)=10-\frac{t}{3} ; h(s)=\sqrt{s-7} ; g(r)=4^{2 r+1} \text { and } f(x)=1+3 x-2 x^{2} \text {. }
$$

The results (in percent) are given by Histograms 5 and 6 for "Correct answers" and the answers "I do not know", respectively for different universities.

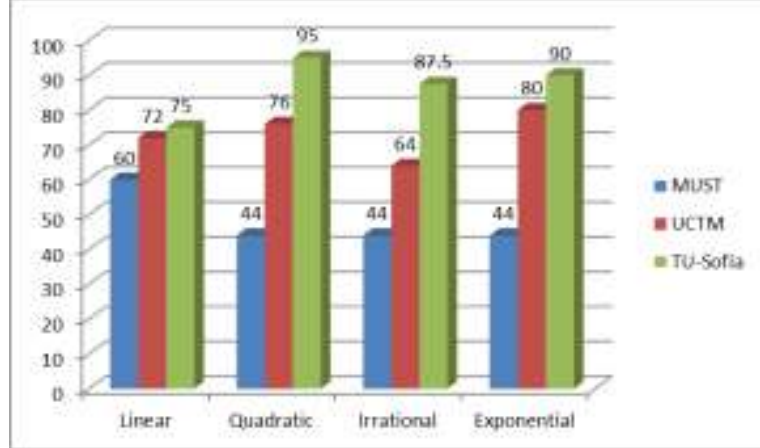

Histogram 5

Correct answers

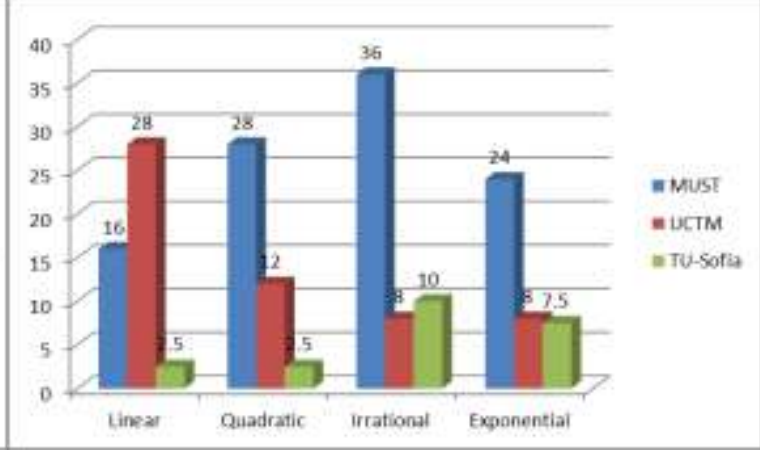

Histogram 6

I do not know

In Example 3, the students have to solve a couple of equations and inequalities. The authors had to distinguish the stages of decisions and different types of errors. The results are given in Table 4. 
About the stability of platform on which we build mathematical knowledge at the engineering ..

\begin{tabular}{|c|c|c|c|c|c|c|c|c|c|c|c|c|c|c|c|}
\hline \multirow[t]{2}{*}{ Problems } & \multicolumn{3}{|c|}{ Correct } & \multicolumn{3}{|c|}{ Calc. error } & \multicolumn{3}{|c|}{ Logical error } & \multicolumn{3}{|c|}{ Incomplete } & \multicolumn{3}{|c|}{ I do not know } \\
\hline & $\mathrm{A}$ & $\mathrm{B}$ & $\mathrm{C}$ & $\mathrm{A}$ & $\mathrm{B}$ & $\mathrm{C}$ & $\mathrm{A}$ & $\mathrm{B}$ & $\mathrm{C}$ & $\mathrm{A}$ & $\mathrm{B}$ & $\mathrm{C}$ & $\mathrm{A}$ & $\mathrm{B}$ & $\mathrm{C}$ \\
\hline$x=2 x^{2}$ & 4 & 9 & 29 & 0 & 1 & 1 & 11 & 5 & 3 & 0 & 2 & 3 & 10 & 8 & 4 \\
\hline $2 / t=t^{2}$ & 0 & 1 & 5 & 0 & 0 & 8 & 7 & 11 & 20 & 6 & 4 & 0 & 12 & 9 & 7 \\
\hline$e^{x}=\sqrt{e}$ & 11 & 11 & 22 & 0 & 1 & 1 & 1 & 1 & 2 & 1 & 0 & 0 & 12 & 12 & 15 \\
\hline $\ln x=-2$ & 4 & 4 & 8 & 2 & 0 & 7 & 2 & 5 & 3 & 0 & 0 & 1 & 17 & 16 & 21 \\
\hline $2^{\sqrt{x-1}}>0$ & 5 & 0 & 19 & 0 & 0 & 2 & 1 & 4 & 9 & 1 & 0 & 1 & 19 & 21 & 9 \\
\hline$|3 s-1|=2$ & 8 & 7 & 19 & 0 & 0 & 1 & 1 & 3 & 4 & 4 & 5 & 1 & 12 & 10 & 15 \\
\hline$x>x^{2}$ & 4 & 5 & 19 & 1 & 0 & 8 & 6 & 10 & 6 & 1 & 1 & 0 & 13 & 10 & 7 \\
\hline $\sin t=-1$ & 3 & 2 & 5 & 0 & 0 & 2 & 4 & 0 & 0 & 1 & 8 & 15 & 17 & 15 & 18 \\
\hline$e^{x} \leq 1$ & 6 & 6 & 19 & 1 & 1 & 3 & 1 & 3 & 5 & 1 & 0 & 2 & 16 & 15 & 11 \\
\hline $\ln x<0$ & 2 & 4 & 7 & 0 & 0 & 4 & 4 & 3 & 1 & 5 & 0 & 1 & 16 & 18 & 27 \\
\hline
\end{tabular}

Table 4

Almost $48.8 \%$ of all students have decided properly equation $e^{x}=\sqrt{e} ; 46.6 \%$ were able to solve $x=2 x^{2}$, and $37.7 \%$ have coped with $|3 s-1|=2$, see Histogram 7 . The results of the best solved examples distributed by the universities are given in Histograms 8.

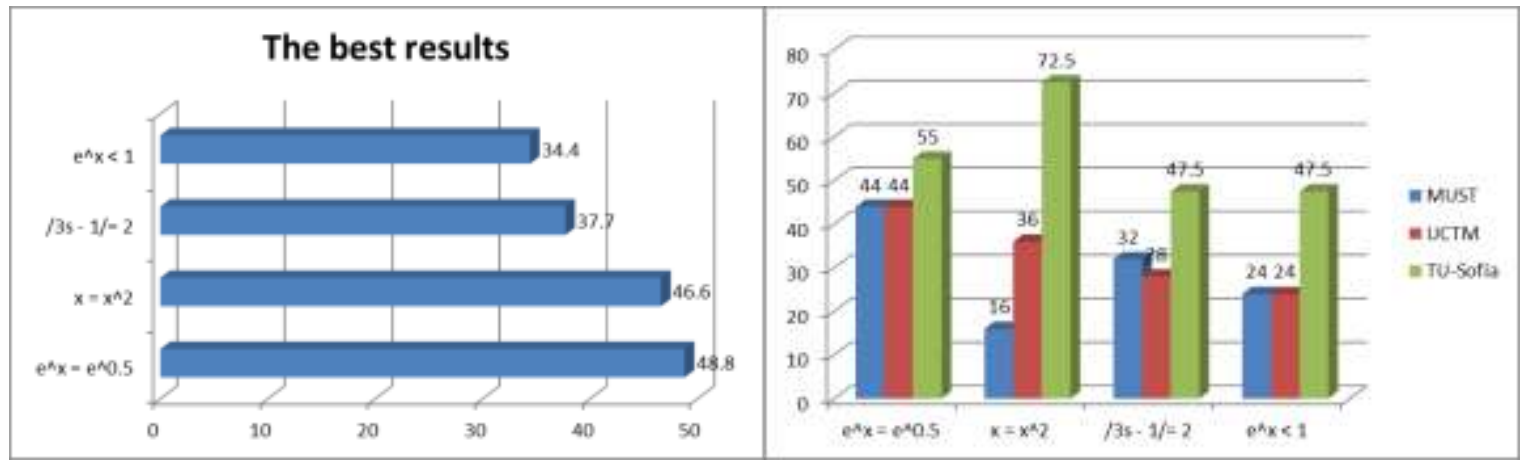

Histogram 7

Histogram 8

The lowest outcomes are obtained for the rational equation $2 / t=t^{2}$, solved by $6.7 \%$ of all the students. Only $8.9 \%$ of the students manage to solve trigonometric equation $\sin t=-1$. Logarithmic inequality $\ln x<0$ and equation $\ln x=2$ are solved by $15.5 \%$ and $17.8 \%$ respectively, see Histogram 9 . The overall results of these "badly solved examples" are given in Histogram 10.

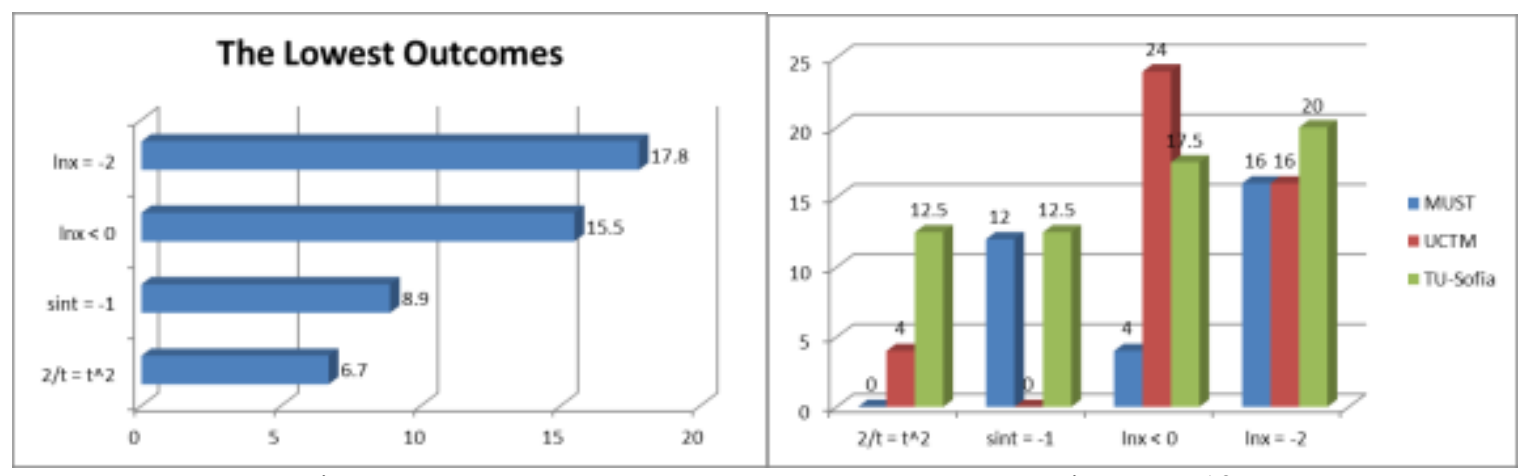

Histogram 9

Histogram 10

About $42.2 \%$ of the students have admitted logical mistakes in equation $2 / t=t^{2} ; 24.4 \%$ have solved wrong the quadratic inequality $x>x^{2}$, and $21 \%$ have not managed with $x=2 x^{2}$, see Histogram 11. The information distributed to the three universities is provided by Histogram 12 . 
About the stability of platform on which we build mathematical knowledge at the engineering ..

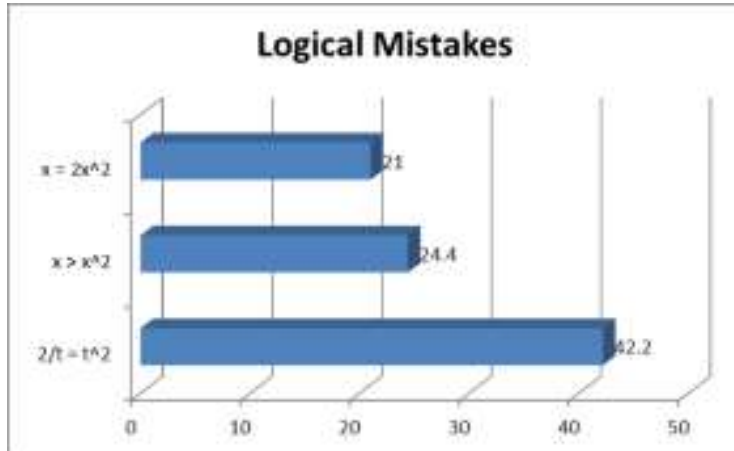

Histogram 11

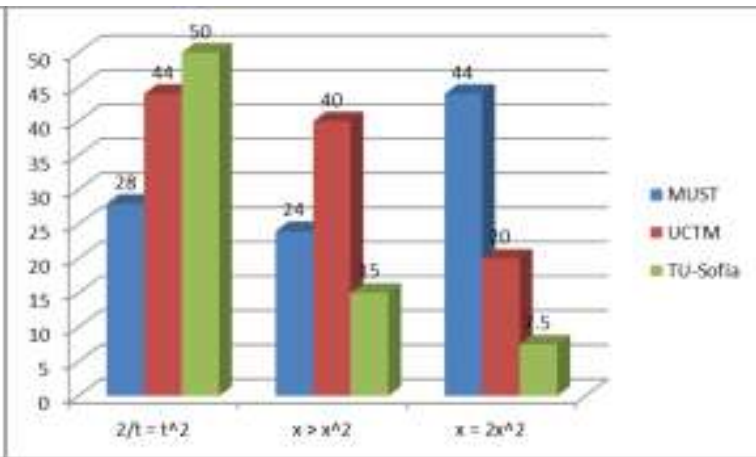

Histogram 12

The most answers "I do not know" are written for the exercises $\ln x<0$; $\ln x=-2$ and $\sin t=-1$, and the results are represented by the Histograms 13 and 14 .

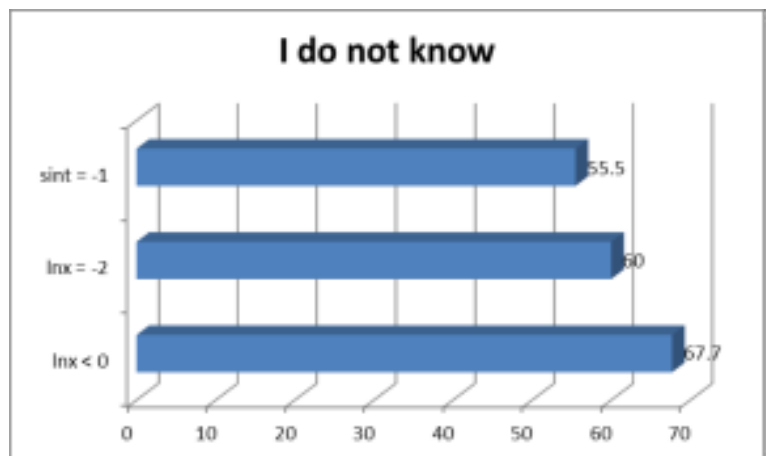

Histogram 13

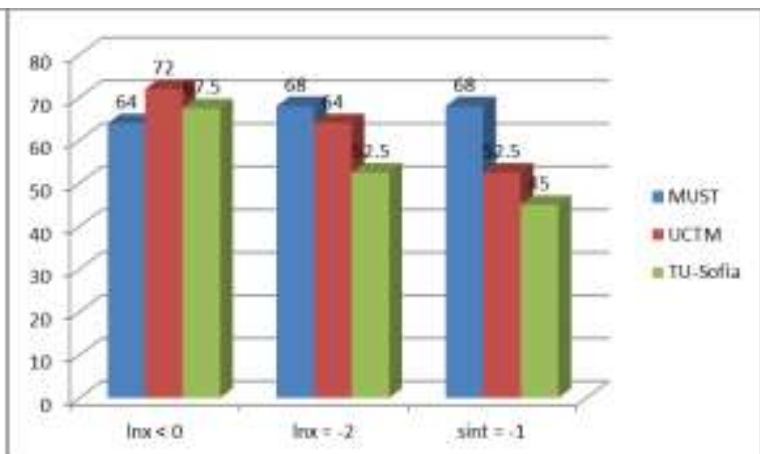

Histogram 14

The highest number of incomplete solutions is in the examples: $\sin t=-1 ;|3 s-1|=2$ and $2 / t=t^{2}$. The results are given in Histograms 15. The summary results are shown in Histogram 16.

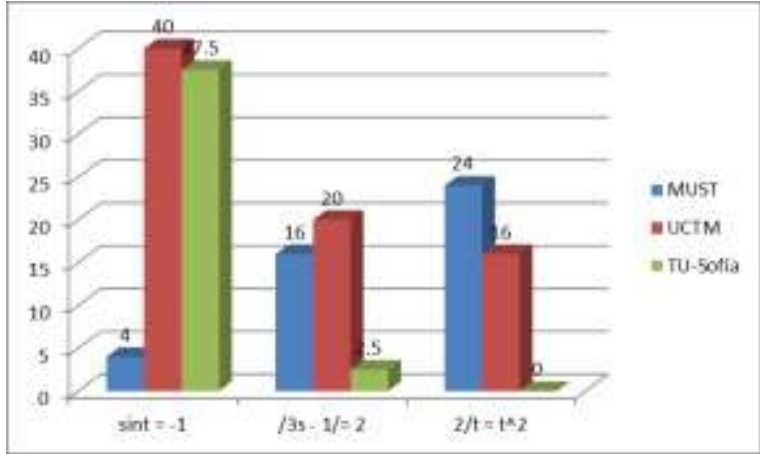

Histogram 15

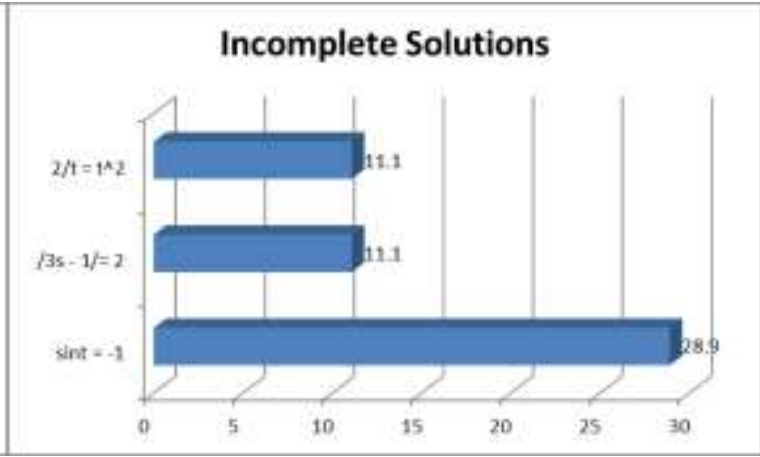

Histogram 16

In Example 4, the students have to find the domain of the given functions. The results obtained are given in Table 5.

\begin{tabular}{|c|c|c|c|c|c|c|c|c|c|c|c|c|c|c|c|}
\hline \multirow{2}{*}{$\begin{array}{l}\text { Example } \\
\text { Correct } \\
\end{array}$} & \multicolumn{3}{|c|}{$\frac{s}{2-3 s+s^{2}}$} & \multicolumn{3}{|c|}{$m(t)=2^{\frac{1}{t}}$} & \multicolumn{3}{|c|}{$g(r)=\sqrt{4 r-r^{2}}$} & \multicolumn{3}{|c|}{$f(s)=\ln \left(s^{2}+1\right.$} & \multicolumn{3}{|c|}{$h(t)=2 t+1$} \\
\hline & 4 & 3 & 19 & 3 & 6 & 26 & 5 & 2 & 15 & 4 & 1 & 12 & 4 & 9 & 29 \\
\hline Calc. error & 0 & 0 & 5 & 0 & 0 & 0 & 0 & 0 & 9 & 0 & 0 & 1 & 0 & 0 & 1 \\
\hline Log. error & 4 & 8 & 1 & 5 & 4 & 2 & 3 & 5 & 5 & 1 & 2 & 3 & 3 & 1 & 0 \\
\hline Incomplete & 0 & 3 & 4 & 0 & 0 & 1 & 1 & 7 & 1 & 0 & 2 & 2 & 0 & 4 & 0 \\
\hline I do not know & 17 & 11 & 11 & 17 & 15 & 11 & 16 & 11 & 10 & 20 & 20 & 22 & 18 & 11 & 10 \\
\hline
\end{tabular}

Table 5 
The weakest results, see Histogram 17 are for the function $f(s)=\ln \left(s^{2}+1\right)$. The overall results for all the students are given in Histogram 18.

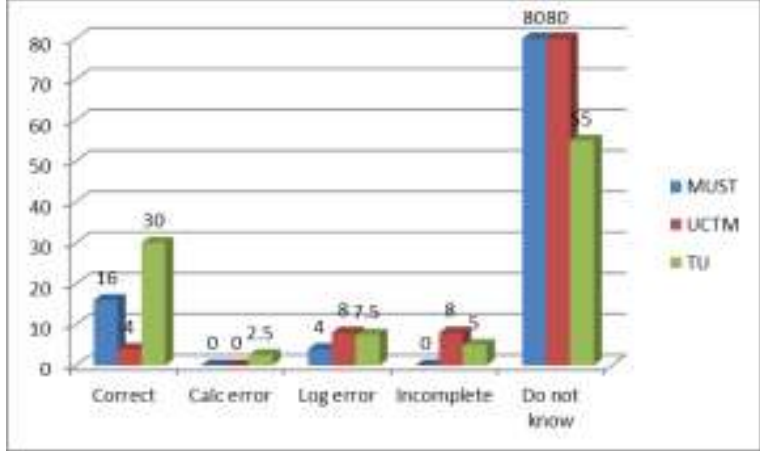

Histogram 17

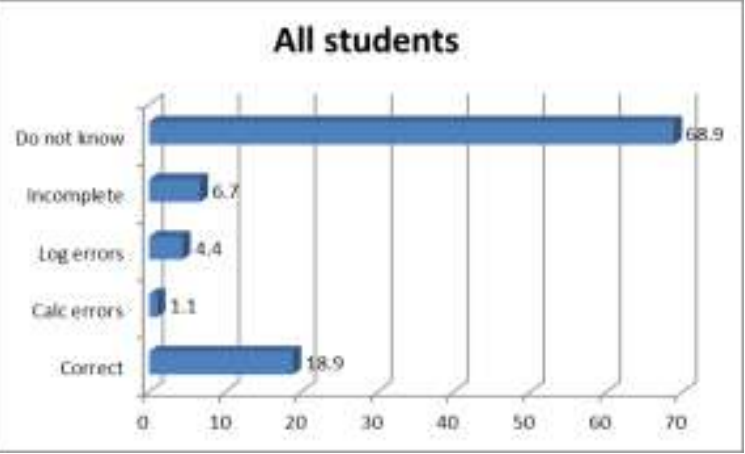

Histogram 18

About $46.7 \%$ of the students define correctly the domain of linear function $h(t)=2 t+1$ and a distribution of the answers are given in Histograms 19, and overall results in Histogram 20.

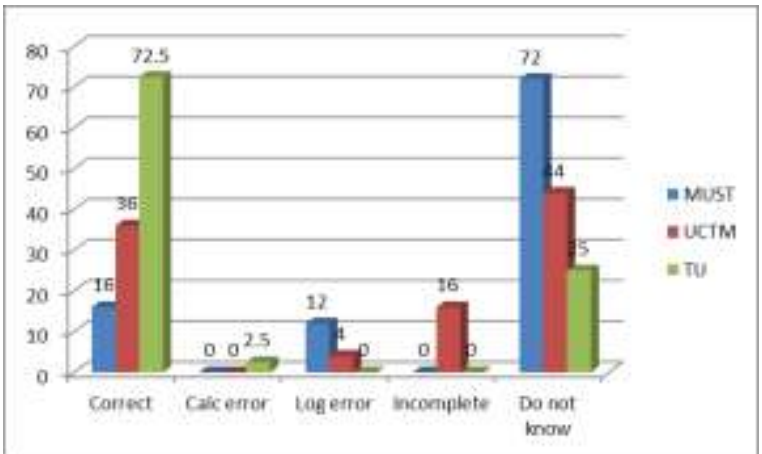

Histogram 19

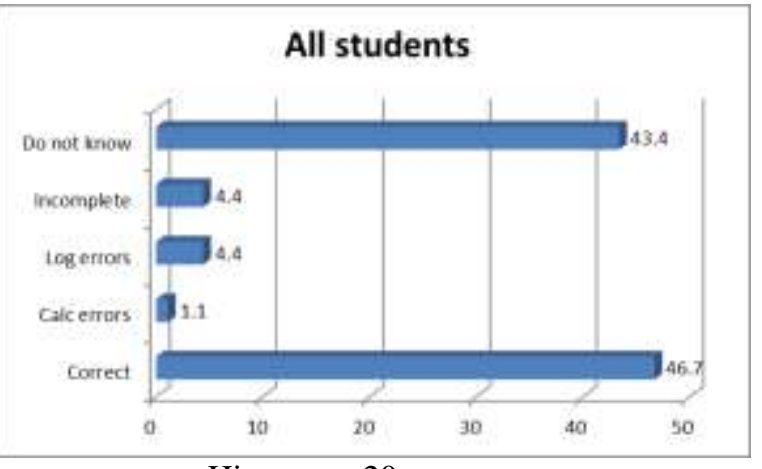

Histogram 20

In Example 5, the students have to sketch the functions: $f(x)=1-2 x$ and $f(t)=(t+1) .(t-3)$.

The results for plotting the linear function are given in Histogram 21 and they are widely divergent from the students' opinions about their knowledge in the first part, see Histogram 22.

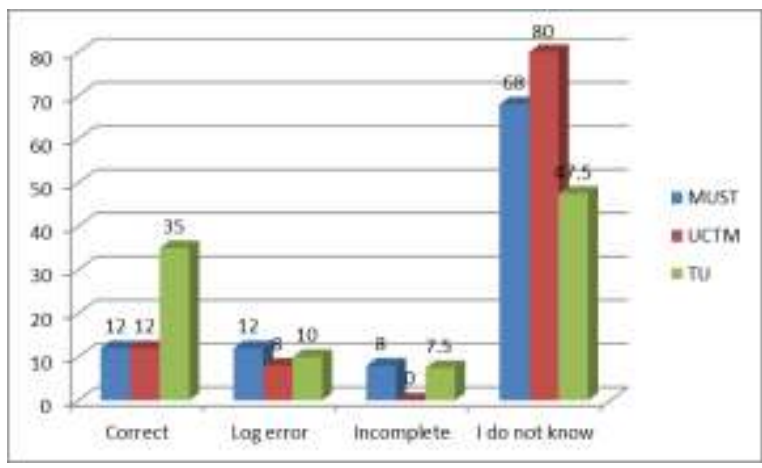

Histogram 21

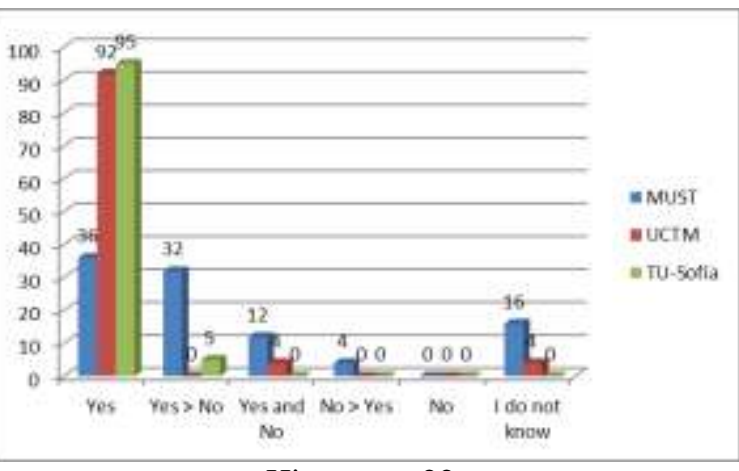

Histogram 22

The difference between the answers "Yes, I know a linear function" in Part 1 and the results of plotting the graph of $f(x)=1-2 x$ in Example 5 is unexpectedly big. 


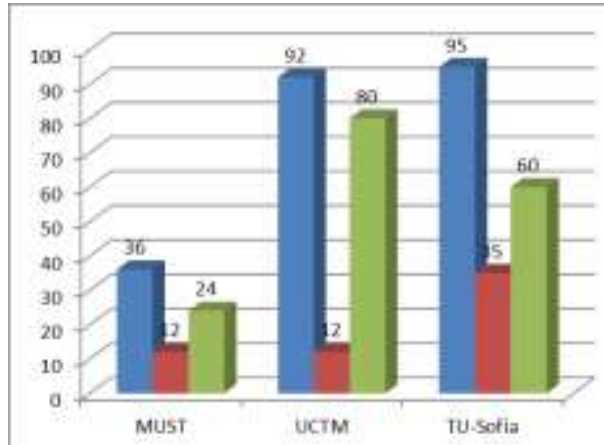

Histogram „Yes, I know” - “Correct solution”

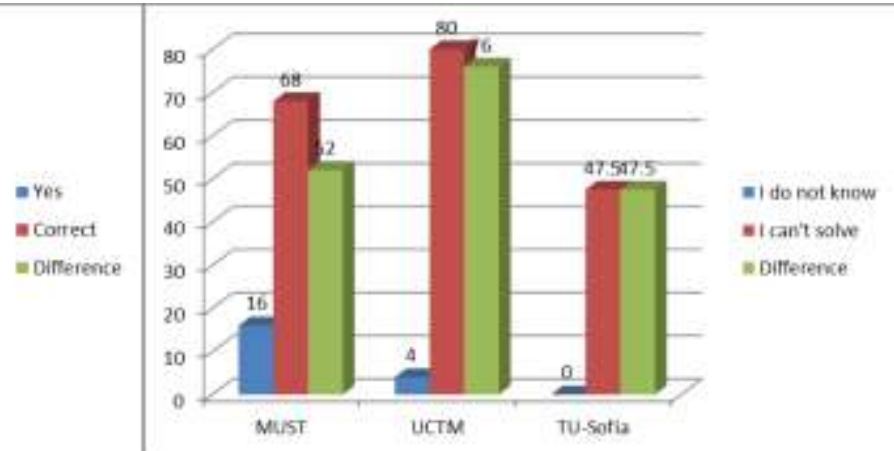

Histogram "I do not know" - "I can’t solve"

$77.7 \%$ of the students claim that they know the concept "Linear function" and only $5.5 \%$ recognize that they do not know it according to Histogram 24. But, only $22.2 \%$ successfully draw the graph of $f(x)=1-2 x$, and $62.1 \%$ recognize that they do not know how to do it, see Histogram 23.

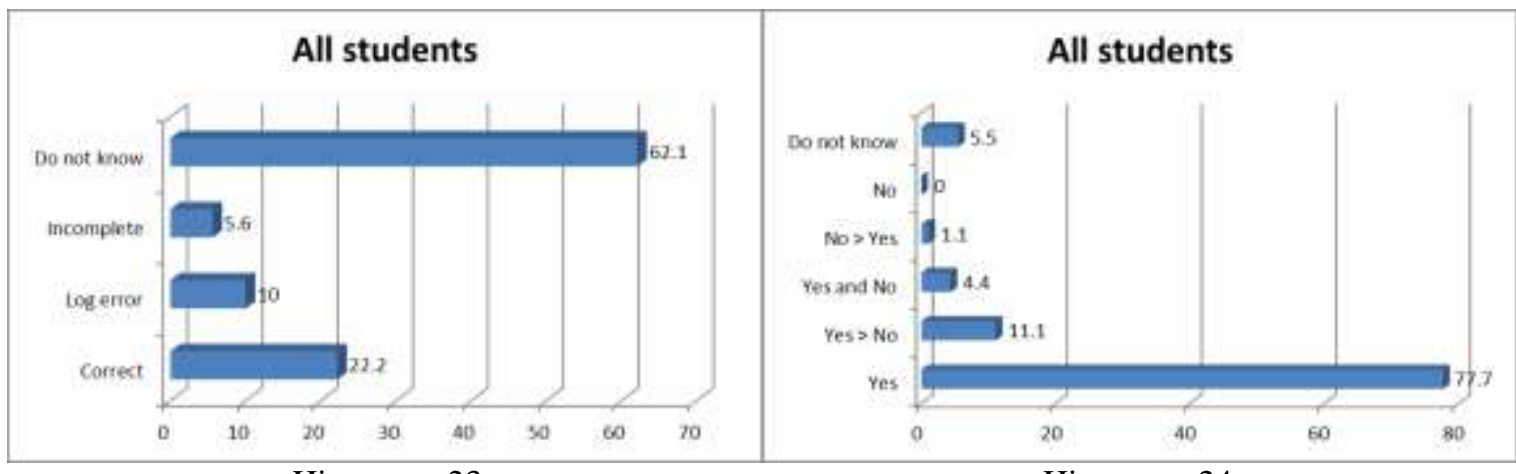

Histogram 23

Histogram 24

The results of the quadratic function are similar to those of linear function.

In Example 6, the students have to determine the graph of "one to one" function.

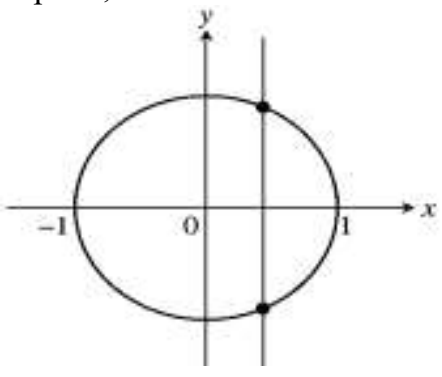

a) $x^{2}+y^{2}=1$

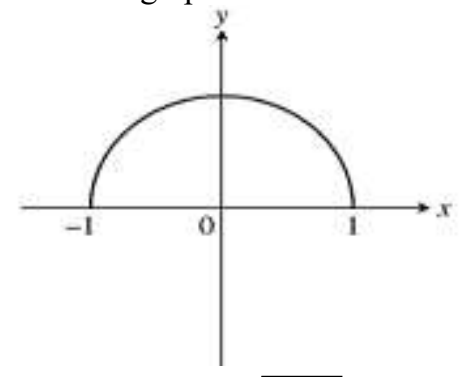

b) $y=\sqrt{1-x^{2}}$;

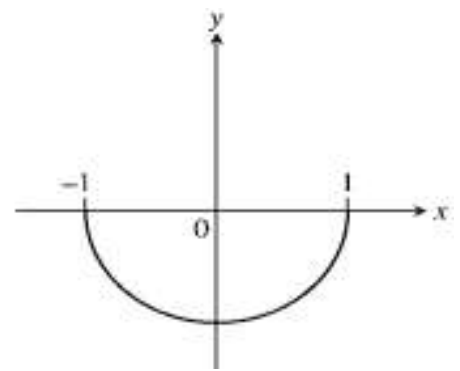

c) $y=-\sqrt{1-x^{2}}$.

Histograms 25 and 26 represent information of different type responses for Ex. $6 \mathrm{a}$ and $6 \mathrm{c}$ for the three universities. Histograms 27 and 28 provide the overview results about the same examples.

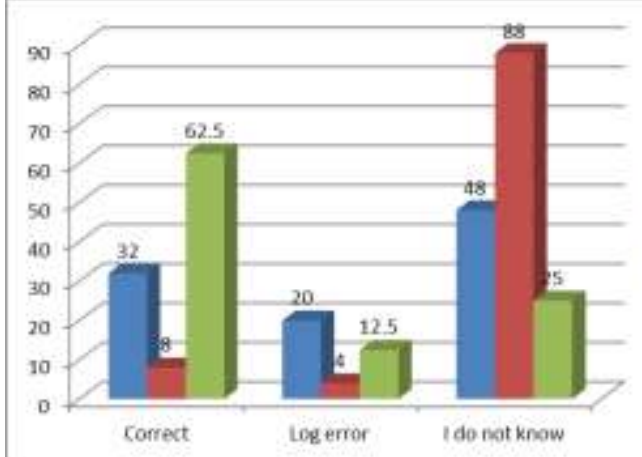

Histogram 25

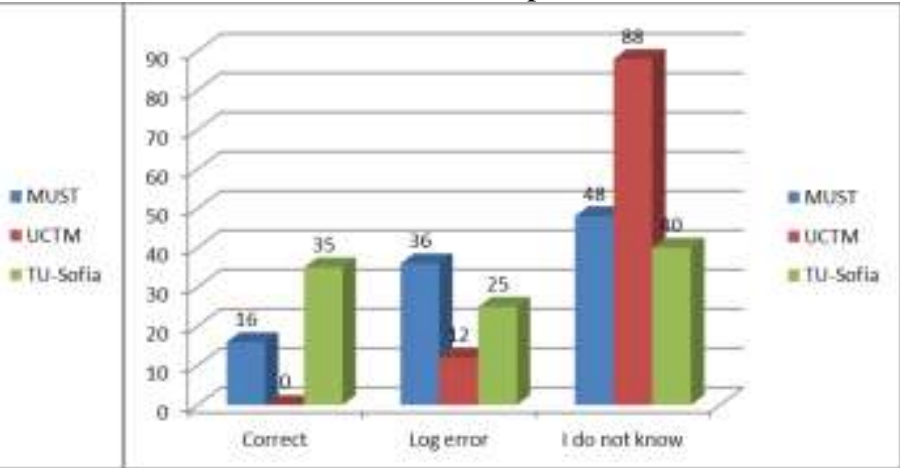

Histogram 26 


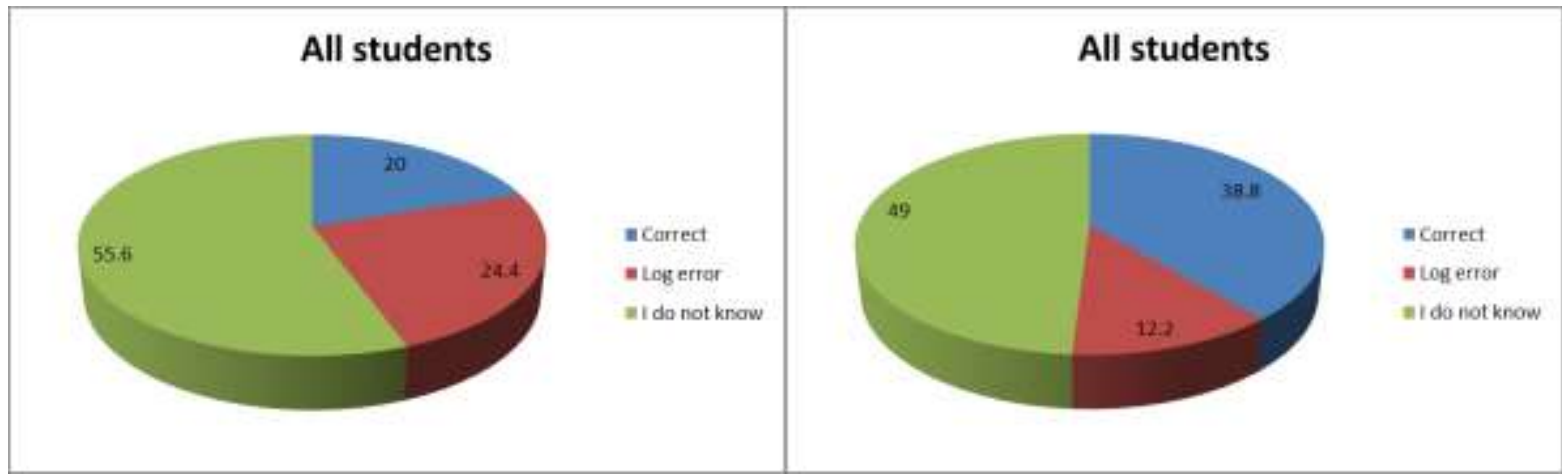

Histogram 27

Histogram 28

\section{Conclusion}

1. The results obtained demonstrate some common gaps for the students of the three universities - logarithms, logarithmic equations and inequalities, trigonometry topics that impede most students and should be involved in a mandatory review.

2. The summarized results show some typical errors in the rational equations and inequalities, negative statements and others. That is possible to overcome by target exercises.

3. The calculations are minimized and they are not subject of our discussion.

4. There are many incomplete decisions in the trigonometric and rational equations and those with absolute value.

5. There is a huge discrepancy between the self-assessments and teachers' assessments, i.e. between the answers in Part 2, where the students give high ratings to their knowledge (answers "YES") and the results of their decisions to the given problems. A similar difference is observed in the responses "I do not know" in the survey and "I can not decide" in the examples.
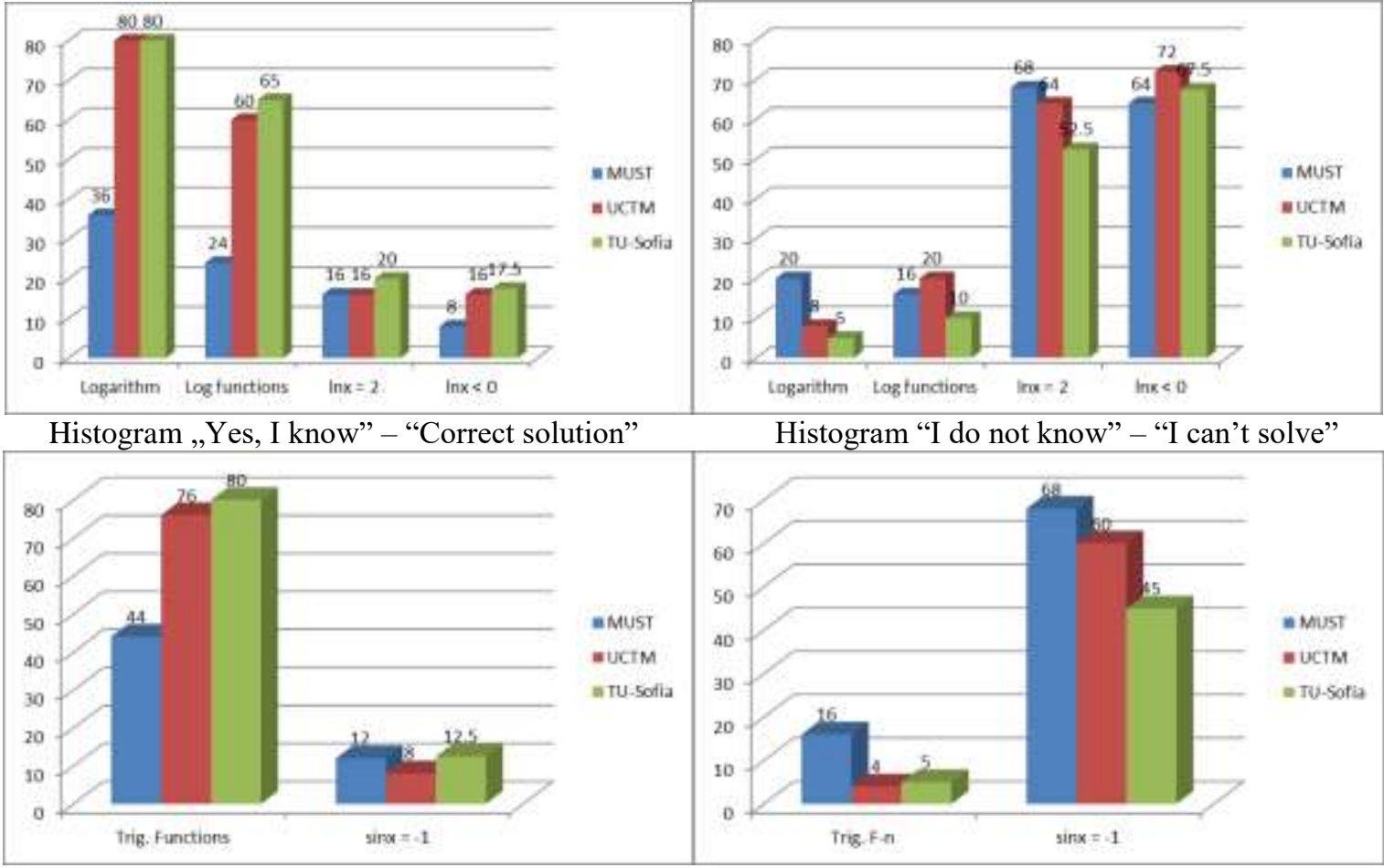

Histogram „Yes, I know” - “Correct solution”

Histogram "I do not know" - "I can’t solve"

There is an inconsistency between the teachers' assessments and self-evaluation in the test. As a result of the conversations with a part of interviewed, the authors found that many students do not know what they should know for a successful training in engineering degree courses. They are not aware of their gaps in knowledge and they could not make a valid "self - assessment". As a result, they do not realize completely that their superficial knowledge with mistakes and omissions would serious hinder their future training. 
About the stability of platform on which we build mathematical knowledge at the engineering ..

We believe that the diagnostic tests in mathematics are one useful guide for the teachers and students also. The organization, stages, and a content of this difficult process of further learning and teaching open a discussion on the following questions:

1. These tests identify the students whose knowledge are insufficient and they need an individual extra help. We believe that the most appropriate time for using such diagnostic tests is before new topics in the groups where the students are admitted with lower scores.

2. The examples included in the test should be determined by the contents, what is necessary for successful study the new topic. The best is to make a "conceptual map" for the links old - new knowledge and skills.

3. We recommend using online tests with two or three parameters depending on different factors so that every student to obtain his own test.

4. The results of the survey differ from actual results of the test and observations. The students tend to indicate always answer (though wrong!) and do not benefit answers "I do not know" or "I can't." This is a result of common used evaluation, where no negative points exist for the wrong answers. Recognition that we do not know something is a first step towards its learning.

\section{Future Work}

Drafting the suitable learning online materials and diagnostic tests collection for key topics included in the bachelor program degree for self-study is a main part of our future work. That will allow every student to pursue his individual growth and to overcome his "own" failures in order to meet the standards set out in the curriculum. Of great importance is the progress of each student to be monitored and evaluated.

Including the appropriate engineering examples and usage of the software programs in the educational materials are important factors for motivation and greater efficiency in teaching mathematics.

Our main goal is to help our students to become active learners, to be able to make correct self - evaluation, to be able to work in a team.

\section{Acknowledgements}

The authors express their gratefulness to The Mongolian University of Science and Technology for the opportunity this survey to be conducted. The second and third authors express their sincere gratitude for the full support by "One more step project funds", EM-ECW, Project "Swap and Transfer", Erasmus Mundus programme Action 2 during their stay at the Mongolian University of Science and Technology, Ulan Bator.

\section{References}

[1]. L. Mustoe, \& D. Lowson, (Editors), Mathematics for the European Engineer A Curriculum for the Twenty-First Century, SEFI Mathematics Working Group, SEFI HQ, Brussells, 2002, ISBN 2-87352-045-0.

[2]. M. Demlova, C. Fant, T. Gustafsson, D. Lawson, L. Mustoe, B. Olsson-Lehtonen, C. Robinson, D. Velichova, A Framework for Mathematics Curricula in Engineering Education, A Report of the Mathematics Working Group, Publisher: European Society for Engineering Education (SEFI), Brussels, 2013, ISBN 978-2-87352-007-6.

[3]. K. Dishlieva, From the Secondary School to the Technical University, or One Difficult Year for the First-Year Students, Bulgarian Journal of Science and Education Policy (BJSEP), 4(2), 2010, 248-275, ISSN 1313-1958.

[4]. K. Dishlieva, "Some Reasons for the lack of Success when Learning Mathematics in Technical Universities and Recommendations for their Overcoming", Bulgarian Journal of Science and Education Policy, 8(1), 2014, 192-215, 2014, ISSN 1313-1958.

[5]. S. Tsedendamba, K. Dishlieva, S. Petkova, Mathematical Preparation at School from the First Year Student's Point of View, Профессор Багш Нарын Эрдэм Шинжилгээний Бутээлийн Эмхэтгэл, УлаанБаатар Хот, 19(183), 2015, 461-466, ISSN 1560-8794.

[6]. S. Tsedendamba, K. Dishlieva, S. Petkova, Problems and Suggestions about Mathematics Education for Engineers from the Students' Point of View, Профессор Багш Нарын Эрдэм Шинжилгээний Бутээлийн Эмхэтгэл, УлаанБаатар Хот, 19(183), 2015, 467-473, ISSN 1560-8794.

[7]. K. Dishlieva, S. Petkova, A. A. Dishliev, T. Petkov. Role of the Preliminary Tests in Mathematics for Adequately Organization of Educational Process, Announcements of Union of Scientists-Sliven, 29(1), 2015, 19-22, ISSN 1311-2864. 